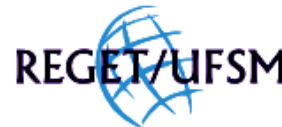

GODOY, WIZNIEWSKY, v(11), no 11, p. 2280-2290 , JUN, 2013.

Rev. Elet. em Gestão, Educação e Tecnologia Ambiental (e-ISSN: 2236-1170)

\title{
SUSTENTABILIDADE AMBIENTAL ATRAVÉS DO CONHECIMENTO E DA INFORMAÇÃO
}

\author{
ENVIRONMENTAL SUSTAINABILITY THROUGH KNOWLEDGE AND INFORMATION
}

\author{
Cristiane Maria Tonetto Godoy, Jose Geraldo Wizniewsky
}

http://dx.doi.org/10.5902/223611708687

\section{RESUMO}

A preocupação contemporânea da sociedade mundial com a questão ambiental e a sua preservação, tem gerado ações que visam garantir e proteger o meio ambiente, e é neste sentido, que a legislação ambiental brasileira atua. Entretanto, para que as normas presentes na legislação ambiental sejam cumpridas e respeitadas é necessário que a população tenha conhecimento e acesso a informação destas normativas. O presente trabalho procurou desvendar quais as percepções e como se constrói o conhecimento dos agricultores familiares do município de Santa Rosa/RS sobre a legislação ambiental. Assim, foi utilizado a técnica de entrevista semiestruturada, realizadas com 30 agricultores familiares do município, sendo quinze agricultores de propriedades ao longo do rio Santo Cristo e 15 agricultores com propriedades no rio Amandaú. O estudo apontou que o cumprimento da legislação ambiental pelos agricultores familiares apresentam alguns limites: o parcial conhecimento ou desconhecimento destes sobre as normativas existentes e a falta de informação, seja no sentido da legislação ou das possibilidades de manejo destas. Para promover o desenvolvimento sustentável é necessário que todos os indivíduos e setores da sociedade possuam acesso a informação e a educação ambiental, para que assim, possa alcançar a sustentabilidade ambiental desejada, além de valorizar os agricultores, promover o desenvolvimento rural, a qualidade de vida e bem-estar das famílias rurais.

Palavras-chave: agricultores familiares, informação, meio ambiente

\begin{abstract}
The biggest concern of society with global environmental issues and preservation, has generated actions aimed at guaranteeing and protecting the environment, and in this sense, the Brazilian environmental legislation acts. However, for the present standards in environmental legislation are met and respected is necessary that the population has access to information and knowledge of these regulations. This study sought to uncover the perceptions and how knowledge is constructed of family farmers in the municipality of Santa Rosa / RS on environmental legislation. Thus, we used the technique of semi-structured interview, conducted with 30 farmers of the county, being fifteen farmers of properties along the river Santo Cristo and 15 farmers with properties in the river Amandaú. The study found that the environmental compliance by family farmers have some limits: the partial knowledge or ignorance on these existing standards and lack of information, whether in law or sense of the possibilities of handling these. To promote sustainable development requires that all individuals and sectors of society have access to environmental information and education, so that, to achieve the desired environmental sustainability, as well as enhancing farmers, promote rural development, quality of life and welfare of rural households.
\end{abstract}

Keywords: family farmers, information, environment 


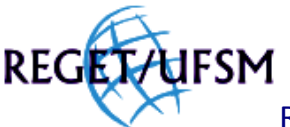

GODOY, WIZNIEWSKY, v(11), no 11, p. 2280-2290 , JUN, 2013.

Rev. Elet. em Gestão, Educação e Tecnologia Ambiental (e-ISSN: 2236-1170)

\section{INTRODUÇÃO}

Formular um conceito fechado sobre o meio ambiente seria incorrer no engessamento da questão ambiental e de toda a rede e ligações que existem nos ecossistemas. O conceito de meio ambiente ainda encontra-se em construção, definido de várias formas pelas diferentes áreas de conhecimentos e especialistas. Ele pode ser considerado não apenas àquele conceito em que se possa estabelecer de modo rígido e definido, mas, compreendido como uma representação social, que evolui no tempo e depende do contexto dos grupos sociais onde será utilizado. Em outras palavras, o meio ambiente e a questão ambiental, seja suas conceituações ou importância dependem de suas contextualizações em determinado período histórico e na sociedade vigente naquele momento.

Jollivet e Pavê (1992) conceituam o termo meio ambiente como o conjunto de componentes químicos, físicos e biológicos aliados ao elemento sociocultural, que podem afetar de forma direta ou indiretamente, em longo ou curto prazo, os seres vivos e as atividades humanas no âmbito global da ecosfera. De uma forma mais ampla, Gliessman (2000) conceitua como aquele ambiente de um determinado organismo que pode ser definido como a soma de todos os fatores bióticos ou abióticos, afetando seu crescimento, desenvolvimento, estrutura e reprodução. Razão porque devemos compreendê-lo como um conjunto dinâmico, em mudanças, e em constante interação entre os fatores.

A legislação brasileira conceitua como meio ambiente, expresso na Política Nacional do Meio Ambiente na Lei Federal no 6.938 de 1981, em seu artigo terceiro, o "conjunto de condições, leis, influências e interações de ordem física, química e biológica, que permite, abriga e rege a vida em todas as suas formas".

Desta forma, pode-se considerar que o meio ambiente é o palco onde as interações entre os diversos organismos, bióticos ou abióticos, acontecem. Portanto, deve ser visto como dinâmico e em constantes transformações. Não somente como o local para as relações humanas, em uma acepção do antropocentrismo, mas reconhecido o direito de preservação de todas as espécies neste meio, em todos possuem papel na extensa teia dos ecossistemas.

Nesse sentido dinâmico do meio ambiente e sua percepção de formas diferentes nos diversos momentos históricos, a questão ambiental, principalmente no que tange a problemática da escassez e destruição dos ecossistemas, começa a ser delimitada como importante, sobretudo com a implantação da Revolução Industrial e do Capitalismo na sociedade moderna.

A saída para a crise ambiental é difícil e complexa. Para Leis (1995), as problemáticas ambientais são efeitos imprevistos pela sociedade, que se encontram unidos ao modelo de desenvolvimento econômico dominante, ou seja, pela ótica do capitalismo industrial, legitimado para atender o aumento das demandas de consumo da população. Que, por sua vez, pressiona os recursos naturais em um planeta com capacidade limitada e finita. Sendo necessária uma visão mais realista e emergencial no que tange o conhecimento dos fatores econômicos, do consumo, do crescimento populacional e do meio ambiente, ao conhecer estes fatores e suas interações é que poderá se tornar viável a transição deste modelo de desenvolvimento para outro mais sustentável. A transição de modelos de desenvolvimento não constitui uma tarefa simples ou fácil, necessita a convergência de uma ótica meramente econômica para uma lógica ecologista, demandando para isto uma mudança no comportamento e pensamento de todos os atores envolvidos, instituições públicas, sociedade civil, mercado, entre outros. 


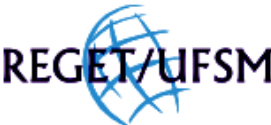

GODOY, WIZNIEWSKY, v(11), no 11, p. 2280-2290 , JUN, 2013.

Rev. Elet. em Gestão, Educação e Tecnologia Ambiental (e-ISSN: 2236-1170)

Das preocupações ambientais surge o conceito de desenvolvimento sustentável, um novo paradigma e modelo a ser adotado pela sociedade. De acordo com Jacobi (2003), esse novo paradigma denominado ecodesenvolvimento, sinônimo de desenvolvimento sustentável, propõe um desenvolvimento que concilie as esferas sociais, ambientais e econômicas de uma forma equitativa.

O conceito de desenvolvimento sustentável terá maior atenção e divulgação nos meios de comunicação, governamentais e acadêmicos com a publicação do documento Our common future, escrito pela Comissão Mundial de Meio Ambiente e Desenvolvimento/CMMAD em meados da década de oitenta (século XX). No Brasil, ficou conhecido como Relatório de Brundtland, publicado em 1987 com o título de "Nosso Futuro Comum". O conceito de desenvolvimento sustentável presente no relatório deve ser entendido como "aquele desenvolvimento que atende às necessidades do presente sem comprometer as possibilidades de as gerações atenderem às suas próprias" (COMISSÃO MUNDIAL SOBRE MEIO AMBIENTE E DESENVOLVIMENTO, 1988). Desde então, o termo tem sido referência para inúmeros trabalhos, discussões e políticas públicas, partindo do princípio do reconhecimento em que vivemos em um planeta cujo sistema é limitado, tornando necessária a criação de alternativas não impactantes para assegurar a qualidade de vida e sobrevivência dos seres humanos e dos ecossistemas. O relatório consta de quatro elementos chaves que comporiam a sustentabilidade ambiental, a pobreza nos países em desenvolvimento, o crescimento da população mundial, a tecnologia e o estilo de vida da sociedade.

A sustentabilidade não deve ser somente técnica, mas também precisa abranger os aspectos empíricos, na metodologia científica e nos aspectos morais. Os avanços científicos apresentam capacidade de encontrar as soluções dos problemas da saúde humana, na oferta tecnológica, produção de alimentos e na engenharia ambiental, como exemplo, a indústria nuclear, a biotecnologia, melhoramento vegetais, entre outros. Mas, podem apresentar conseqüências negativas, tais como: contaminação de água e ar, agricultura intensiva, aquecimento global, perda da biodiversidade, entre outros. Devemos conhecer e reconhecer os limites ecológicos (FUNTOWICZ E MARCHI, 2000). A sustentabilidade não pode ser vista como um estágio final e sim como um processo contínuo capaz de sofrer transformação ao longo do tempo (ROBINSON, 1990 apud DIEGUES, 1992).

Portanto, o desenvolvimento sustentável dever ser compreendido como aquele desenvolvimento com uma maior participação e mobilização da sociedade e governos na busca de um novo conceito de desenvolvimento. $\mathrm{O}$ qual está baseado em indicadores qualitativos e não mais quantitativos, bem como, alternativas mais sustentáveis, ao longo prazo, promovendo assim um equilíbrio entre os diversos ecossistemas e biodiversidade existentes, garantindo a qualidade de vida e a perpetuação principalmente do homem, pois ele é um dos elementos integrados ao meio ambiente.

Santos (2007) relata que vários setores da sociedade se organizam em defesa das questões sociais e ambientais, cobram das pessoas, empresas e governos posturas ambientalmente corretas. Para acompanhar essas exigências, as organizações adotam formas de avaliar, controlar os riscos e os impactos das suas atividades sobre o meio ambiente. Como por exemplo, a implantação de sistemas de gestão ambiental a adequação à legislação e às normas vigentes.

Dessa forma, surgem estratégias na busca pela sustentabilidade para consolidar este "novo" desenvolvimento e enfrentar a crise do esgotamento/degradação dos recursos naturais. 


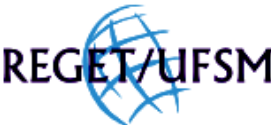

GODOY, WIZNIEWSKY, v(11), no 11, p. 2280-2290 , JUN, 2013.

Rev. Elet. em Gestão, Educação e Tecnologia Ambiental (e-ISSN: 2236-1170)

Alguns exemplos de estratégias podem ser utilizados: as políticas públicas, a educação ambiental, o planejamento energético, o controle de poluição e de dejetos, entre outras, podendo ser ou não regulamentadas por leis e normas.

A legislação existirá para regulamentar essas atividades, partindo do pressuposto que a garantia de qualidade de vida e a preservação do meio ambiente sejam de patrimônio público, por isso, deve ser assegurado e protegido.

O Brasil teve seu primeiro Código Florestal em 1934, Decreto n.o 23.793, utilizado para regulamentar o uso das florestas e classificar os atos danosos ao meio ambiente, como contravenções penais (AHRENS, 2003). O segundo Código Florestal Brasileiro (C.F.B.) foi a Lei no. 4.771, 15 de setembro de 1965, sendo este modificado no ano de 2012. Assim, atualmente o país encontra-se normatizado pela Lei $n-12.727$, que apresenta em suas normativas duas áreas de proteção nas propriedades: a Reserva Legal (R.L.), que visa o uso sustentável dos recursos naturais existentes à conservação e a reabilitação dos processos ecológicos, à conservação da biodiversidade e ao abrigo e proteção da fauna e flora nativas, e as Áreas de Proteção Permanente (APP's), cujas áreas protegidas têm como função a preservação dos recursos hídricos, da paisagem, da estabilidade geológica, da biodiversidade, do fluxo gênico de fauna e flora, proteção do solo e garantia do bem-estar da sociedade. Essas normativas previstas em lei possuem valores e delimitações estipuladas de áreas a serem protegidas nas propriedades rurais.

Portanto, as propriedades rurais encontram-se atreladas a uma legislação que prevê áreas distintas que devem ser preservadas no seu interior, e o não cumprimento desta exigência acarreta aos agricultores familiares sanções e penalidades previstas na Lei, ou seja, a presença da Reserva Legal e das Áreas de Proteção Permanente. A Política Nacional do Meio Ambiente prevê três categorias de instrumentos de gestão ambiental pública (Instrumentos Regulatórios e Punitivos; Instrumentos de Mercado ou Incentivos Econômicos e Instrumentos de Informação), o que a torna composta por instrumentos de comando e controle, ou seja, por normas e padrões que, se descumpridos, acarretam punição prevista em lei.

Assim, a problemática que envolve a legislação ambiental e a agricultura familiar conta com alguns pontos fundamentais: os efeitos da aplicação de uma legislação rígida, que atinge homogeneamente todo o rural e todas as unidades de produção; a desconsideração das consequências da proibição de determinadas práticas para a reprodução econômica e social dos agricultores. O que, ao fornecer alternativas de mudanças como a falta de adequação teórico/prática da legislação ambiental, os induz a práticas contrárias à preservação ambiental (já que muitas propriedades têm dificuldades para se adequarem à legislação por causa do relevo; tamanho das propriedades); a burocracia para a regularização do imóvel junto aos órgãos ambientais competente e a falta de conhecimento da legislação.

Dessa forma, dependendo da localização das propriedades os agricultores familiares estão atrelados às duas exigências que a legislação ambiental normatiza. Nesse contexto, é de suma importância que seja realizados estudos e discussões sobre a legislação e sua aplicação no que tange as propriedades familiares e a qualidade da preservação ambiental para a presente sociedade e para as futuras gerações. Encontrando meios e incentivos para que a legislação e a preservação ambiental sejam viáveis economicamente em seu cumprimento e que possibilite o desenvolvimento sustentável da agricultura familiar. Isso só será possível se os procedimentos hoje empregados tenham alternativas economicamente viáveis, caso contrário, os produtores rurais que dependem destas áreas para sua subsistência, terão dificuldades para se adequarem 


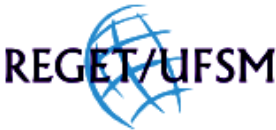

GODOY, WIZNIEWSKY, v(11), no 11, p. 2280-2290 , JUN, 2013.

Rev. Elet. em Gestão, Educação e Tecnologia Ambiental (e-ISSN: 2236-1170)

aos padrões estabelecidos pela legislação ambiental, outra alternativa seria uma forma de compensação aos agricultores familiares, pela preservação de áreas.

\title{
METODOLOGIA
}

O município de Santa Rosa encontra-se localizado no Estado do Rio Grande do Sul, com as

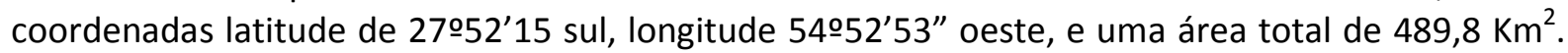
Segundo o Instituto Brasileiro de Geografia e Estatística (IBGE, 2010) a população estimada do município é de 66.059 habitantes. Deste total, aproximadamente $87,7 \%$ dos habitantes residem na área urbana e $12,3 \%$ residem na área rural do município. A matriz produtiva da região encontra-se caracterizada principalmente nos cultivos da soja, milho e trigo, ou seja, por commodities, além de ser expressiva no rebanho bovino, destinado a produção de leite e de corte.

Para compreender como a legislação ambiental tem impactado os agricultores familiares e como estes percebem e se relacionam com os recursos naturais, tornou-se necessário a aplicação de uma metodologia que permitisse mapear e compreender as relações indivíduo/meio ambiente, principalmente no que tange às percepções, o conhecimento e a ligação com a terra. Partindo desta concepção, optou-se por utilizar neste trabalho o pluralismo de técnicas e métodos, por compreender que a utilização combinada destes permite um enriquecimento das interpretações e possibilita uma visão mais abrangente da problemática proposta no presente estudo. Ao combinar técnicas qualitativas e quantitativas, a pesquisa torna-se mais ampliada minimizando assim os problemas do uso isolado das técnicas, além de complementar o olhar do pesquisador um contexto em que o fenômeno da pesquisa acontece.

Ainda neste sentido, Olabuénaga $(1999$, p. $17 ; 111)$ ao abordar sobre o pluriarismo de metodologias traz reflexões sobre o tema, como se segue:

\begin{abstract}
La metodología cualitativa es tan válida como la cuantitativa y su diferencia estriba en la diferente utilidad y capacidad heurística que poseen, lo que les hace recomendables en casos y situaciones distintas [...] la metodología cualitativa no es incompatible con la cuantitativa, lo que obliga a una reconciliación entre ambas y recomienda su combinación en aquellos casos y para aquellos aspectos metodológicos que la reclamen. Esta combinación recibe el nombre de triangulación y es utilizada cada vez con mayor insistencia. [...] La triangulación, en realidad, se utiliza cuando se aplican varias "técnicas" para un solo propósito o trabajo.
\end{abstract}

No presente estudo, utilizou-se a metodologia quantitativa como aporte ao levantamento de dados primários e secundários para a seleção da área da pesquisa no meio rural do município de Santa Rosa/RS. A seleção das propriedades familiares foi através de mapas da região e materiais didáticos disponíveis, selecionando para as entrevistas aquelas que possuíssem suas divisas com o rio Amandaú e o rio Santo Cristo, ambos pertencentes ao município de Santa Rosa/RS.

O rio Amandaú/RS e o rio Santo Cristo/RS, segundo dados da Secretaria do Meio Ambiente do Estado do Rio Grande do Sul/SEMA (2010) fazem parte da Bacia Hidrográfica Turvo Santa Rosa - Santo Cristo, situa-se a norte-noroeste do Estado do Rio Grande do Sul, localiza-se na região fisiográfica do Alto Uruguai, estendendo-se, ainda, por uma pequena área das Missões. 


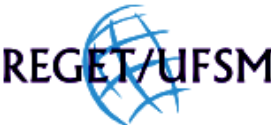

GODOY, WIZNIEWSKY, v(11), no 11, p. 2280-2290 , JUN, 2013.

Rev. Elet. em Gestão, Educação e Tecnologia Ambiental (e-ISSN: 2236-1170)

Tendo como limites ao norte e oeste o Rio Uruguai (fronteira com a Argentina); ao sul a bacia do Ijuí-Piratinim-Icamaquã; e ao leste com a bacia do Passo Fundo Várzea. Ocupa uma área total de superfície de aproximadamente $8.512,20 \mathrm{~km}^{2}$, compreendendo os municípios gaúchos de Horizontina, ljuí, Porto Xavier, Santa Rosa, Santo Ângelo, Santo Cristo e Três de Maio. A bacia é composta pelos Rios Turvo, Guarita, Ogarantin, Buricá, Santa Rosa, Santo Cristo, Amandaú e Comandaí, seu uso é destinado principalmente para a dessedentação animal, abastecimento humano e irrigação das propriedades.

Dessa forma, a escolha das propriedades familiares justifica-se pela presença desses rios, e por estes serem expressivos na sua importância para a região, ou seja, a preservação e conservação do leito incidir diretamente nas propriedades onde ele possui cruza. Principalmente, pela existência das normativas no Código Florestal Brasileiro (C.F.B.), que são as áreas de Reserva Legal (R.L.) e Áreas de Proteção Permanente (APP's). Ambos os rios possuem características semelhantes, tais como: a largura entre as margens de aproximadamente cinco metros, profundidade e importância para a região.

Para compreensão da subjetividade das relações sociais e da relação do agricultor com a legislação ambiental e suas normativas, bem como as construções simbólicas da formação da percepção ambiental e do conhecimento, optou-se por utilizar a metodologia qualitativa. Nela, os pesquisadores estudam a realidade no seu contexto real ou natural, tentando interpretar e compreender os fenômenos e os significados para os indivíduos envolvidos no contexto.

Entre as várias estratégias existentes na metodologia qualitativa, optou-se pela utilização do método denominado etnográfico, pelo mesmo permitir um melhor posicionamento do olhar sobre os sujeitos da pesquisa, a fim de possibilitar a percepção dos fatores sociais, partindo das compreensões e entendimentos dos agricultores familiares. A etnografia deve ser entendida como o método de investigação, no qual se apreende o modo de vida de um núcleo social. É através da etnografia que encontramos a descrição e reconstrução analítica do caráter interpretativo de uma sociedade, cultura ou estrutura social.

Para esse estudo, utilizou-se como técnica a observação participante, por entender que esta técnica permite a obtenção de informações sobre um fenômeno ou acontecimento, tal e como ele se produz. As informações, muitas vezes, não podem ser percebidas somente através das falas, mas, através das ações dos indivíduos e pela entrevista semiestruturada, por essa auxiliar a obtermos informações dos indivíduos quanto as suas percepções, sentimentos e opiniões sobre determinado assunto.

Desenvolveu-se o uso das entrevistas semiestruturadas a partir de um roteiro previamente delimitado, com perguntas abertas, permitindo aos atores entrevistados responderem livremente, dando espaço aos mesmos de expressarem e colocarem as próprias percepções e conhecimentos sobre os questionamentos realizados, enriquecendo, dessa forma, a investigação. Os questionamentos foram realizados para desenvolvermos as várias percepções acerca da questão ambiental e da legislação ambiental. As entrevistas foram efetuadas em três eixos chaves, dispostos da seguinte forma:

Grupo A - Constituído por quinze agricultores familiares que possuem propriedades com a divisa com o rio Santo Cristo, e que, portanto, foram notificados sobre a mata ciliar ao longo do rio e que apresentam as áreas de proteção permanente, reconstituídas de acordo com a normativa existente no Código Florestal. E ao serem fiscalizados, esses agricultores foram 


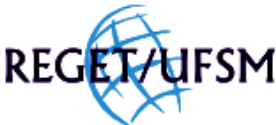

GODOY, WIZNIEWSKY, v(11), no 11, p. 2280-2290 , JUN, 2013.

Rev. Elet. em Gestão, Educação e Tecnologia Ambiental (e-ISSN: 2236-1170)

informados sobre o Código Florestal, tanto pela Patrulha Ambiental, quanto pela promotoria pública.

Grupo B - composto de quinze agricultores familiares, cujas propriedades têm divisa com o rio Amandaú, são propriedades que não sofreram fiscalização por parte de nenhum órgão ambiental e, desse modo, as áreas destinadas a APP's não se encontram cercadas ou restauradas. Nesse eixo, como não foi fiscalizado os agricultores não receberam informações sobre o Código Florestal pelos órgãos ambientais responsáveis pela fiscalização ou pela promotoria.

Grupo C - delimitado pelos promotores do Ministério Público, por possuírem informações referentes aos processos das fiscalizações e o cumprimento da legislação ambiental no rio Santo cristo.

\section{RESULTADOS E DISCUSSÃO}

Para que haja a incorporação de uma consciência mais ecológica e projetos mais sustentáveis é necessário, primeiramente, que passe pela compreensão da subjetividade do comportamento, mudanças de valores e percepções dos indivíduos. Isto é, criem-se significados e visões de mundo derivados de vários fatores, sejam sociais, políticos, econômicos, culturais, étnicos e outros. Entretanto, para que o indivíduo promova mudanças em seu comportamento, em primeiro lugar deve sentir-se afetado pelo risco, sensibilizado de alguma forma. Entendendo, que se tal mudança não ocorrer quem irá sofrer as consequências será ele próprio, e assim, capaz de provocar a modificação que o pensamento ambiental exige.

Para Rohleder et al. (2003) é preciso que os indivíduos modifiquem suas maneiras de agir em todos os aspectos de suas vidas. Desta forma, para a mudança das percepções é necessário essencialmente, que as pessoas mudem suas crenças e atitudes, sendo a informação e a educação os pontos chaves que devem ser observados.

De acordo com Leff (1998), o valor ambiental depende da formação de consciências coletivas e ambientais, fundamentando-se nos princípios éticos, valores políticos e de equidade social, para então haver a preservação do meio ambiente e o real valor desses. A percepção do problema ambiental não é homogênea, frente a isso emerge a necessidade de uma conscientização global quanto à importância da natureza, respeitando as diversas culturas.

Para que os indivíduos possam mudar suas percepções e atitudes no que se refere a sua relação com os recursos naturais acredita-se que, primeiramente, é necessário o acesso à informação, conhecer sobre o assunto e estar informado. Como consequência, há a conscientização e a educação efetivas na construção de novas relações e no novo modelo de desenvolvimento que se busca. Portanto, a informação é um item basilar para o desenvolvimento sustentável.

Barreto (1994), ao escrever sobre a informação, aponta este como instrumento modificador da consciência e da sociedade como um todo. Uma vez que a informação é assimilada de forma adequada, irá produzir conhecimento, modificando o estoque mental de informações do indivíduo, trazendo benefícios para o seu próprio desenvolvimento, bem como da sociedade onde ele integra. A informação deve ser o agente mediador na produção do conhecimento. Assim, podemos formular que operacionalizamos a produção de informações através de práticas e atividades bem definidas. Afinal o indivíduo deve ter contato com as notícias ou dados para que 


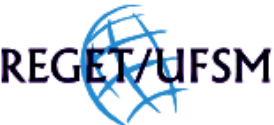

GODOY, WIZNIEWSKY, v(11), no 11, p. 2280-2290 , JUN, 2013.

Rev. Elet. em Gestão, Educação e Tecnologia Ambiental (e-ISSN: 2236-1170)

possa converter as informações em conhecimento e posteriormente as suas crenças. Nesse sentido, reforçamos que o termo informação não deve ser entendido como sinônimo de conhecimento ou aprendizagem, mas deve ser considerado como o primeiro passo na formação de uma posição própria e de uma visão de mundo.

Ao pensarmos a legislação ambiental como uma das estratégias que visa regular as relações da população com os recursos ambientais, iniciamos esta pesquisa indagando qual seriam os conhecimentos dos agricultores familiares quanto às normativas que constam na lei e que incidem nas propriedades. E ainda, qual o conhecimento destes em relação às áreas de preservação permanente e a reserva legal, bem como as terminologias presentes no Código Florestal.

Observou-se que a maioria dos agricultores familiares que residem no rio Amandaú (grupo B), portanto aquelas propriedades que não sofreram fiscalização, conhecem parcialmente ou desconhecem as terminologias e as incidências do Código Florestal. Os produtores que conhecem parcialmente sabem que a legislação ambiental apresenta, em sua normativa, a existência das áreas de proteção ao longo dos rios, mas, na sua maioria não saberiam a nomenclatura ou valores (metragem) dessa área. Ao compararmos com as entrevistas realizadas com os agricultores do rio Santo Cristo (grupo A) notamos que todos conhecem a terminologia e os valores que devem ser preservados no que se refere às áreas de preservação permanente (APP's). De fato, ao avaliarmos o porquê os agricultores do grupo A possuem um melhor e maior conhecimento sobre a normativa no que se refere às APP's, as incidências e valores estipulados pela lei, defrontamos com o fato das propriedades com divisas no rio Santo Cristo sofreram fiscalização nas suas áreas de preservação permanente e, ao sofrerem essa vistoria foram repassadas informações referentes ao que a legislação impõe no que tange às áreas de APP's.

Quanto às áreas de proteção permanente no rio Santo Cristo, por ter havido a fiscalização, todas as propriedades encontram-se com os 30 metros cercados e a área de mata ciliar já tinham as APP's de acordo com que a legislação prevê ao longo do rio. Podemos visualizar in loco que estas áreas estão em plena de recuperação da mata ciliar ao longo do rio, nascentes e olhos d'água. Entretanto, cabe ressaltar que apenas a imposição de uma normativa não significa mudança de percepção, paradigma e qualidade da área preservada.

Em relação às áreas de proteção permanente no rio Amandaú, a maioria das propriedades possui alguma área de preservação da mata ciliar ao longo do rio, no entanto, muitas propriedades visitadas estão aquém do que a legislação normatiza.

Ao referenciar, durante as entrevistas, sobre as áreas de reserva legal e sua normativa para as propriedades rurais, pode ser percebido que ao contrário das APP's, a reserva legal é quase desconhecida pelos agricultores. Dos 30 entrevistados apenas sete agricultores conhecem parcialmente a normativa, entendem que a propriedade deve ter uma área preservada e que não pode ser manejada. Assim, no que se refere a porcentagem, averbação e a possibilidade de manejo dessas áreas, estes agricultores desconhecem.

As informações constantes na legislação ambiental não são de conhecimento dos agricultores familiares e nem as possibilidades existentes para esta categoria social são repassadas, no sentido de informá-los sobre as exigências legais que a propriedade teria. Foram encontradas ao total quatro propriedades que possuem a reserva legal, entretanto, estas áreas não foram averbadas ou não constam no registro de imóveis, pelo desconhecimento dos agricultores da normativa. Os agricultores desconheciam que a área poderia ser manejada de 


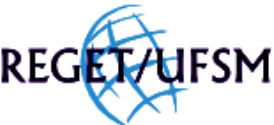

GODOY, WIZNIEWSKY, v(11), no 11, p. 2280-2290 , JUN, 2013.

Rev. Elet. em Gestão, Educação e Tecnologia Ambiental (e-ISSN: 2236-1170)

forma sustentável, ou realizar plantios de árvores frutíferas. Para ilustrar, ao perguntar por que o agricultor havia deixado uma área preservada, já que o mesmo desconhecia sobre a reserva legal, o mesmo respondeu que era para preservar a natureza, para que seus netos pudessem usufruir o que ele tinha usufruído na infância, ou seja, manter a qualidade de vida para a geração futura.

Já a discussão sobre a nova legislação ambiental, todos os agricultores ouviram comentários, através do rádio ou da televisão, mas não fazem a ligação entre as terminologias Código Florestal e legislação ambiental. E, na sua maioria, não sabem maiores informações sobre o que se encontra na pauta da discussão.

Ao longo das entrevistas pode-se perceber aqueles agricultores que possuem um maior conhecimento sobre as normativas constantes na legislação ambiental brasileira, são aqueles que participam ativamente de alguma cooperativa ou sindicato e que nestas instituições são discutidos sobre as normativas ou mesmo informadas sobre estas. Além disso, que estes institutos/órgãos promovem cursos de capacitação ou de informação no que tange as práticas de manejo mais sustentáveis ou apenas cursos para informar diversos assuntos, que incluem na pauta o meio ambiente, a água, uso de agrotóxicos, entre outros.

Sendo assim, estes resultados nos fazem refletir sobre o papel fundamental que a informação tem na construção do conhecimento e nas mudanças de comportamentos e nas relações indivíduos/meio ambiente. Aqui, voltamos ao ponto do desconhecimento ou conhecimento parcial sobre a legislação ambiental por parte dos agricultores familiares, pois essa "quase ausência" de informação nos propicia uma reflexão da intensidade da cobrança da lei que está sendo realizada, uma vez que a maioria não tem total conhecimento sobre as normativas e valores estipulados, não dimensionando, portanto as suas implicações em termos de não cumprimento das normas.

Ao analisar historicamente a evolução do o meio rural e a modernização da agricultura pode-se afirmar que o campo sofre basicamente duas pressões: para utilizar os insumos produzidos pelas indústrias tal como o uso dos agrotóxicos, sementes geneticamente modificada, mecanização, entre outros; e em segundo, a ampliação das áreas agricultáveis pelos agricultores, sendo legitimado e incentivado pelos órgãos competentes e pela sociedade principalmente a partir da década de sessenta (século XX).

Segundo Soares et al. (2004), a orientação assumida pelo Estado Brasileiro estava ancorada na manutenção e ampliação de territórios, exercendo sobre estes ações predatórias e exploratórias dos recursos naturais. Seguindo a lógica produtivista-capitalista, muitas propriedades acabaram por desmatar as áreas florestais ou os campos para destinar estas áreas para as lavouras ou a criação de gado, e esta é a situação que se encontram a maior parte das propriedades rurais brasileiras. A informação ou até mesmo a crença divulgada há tempos atrás era justamente contrária à preservação das áreas, aliás, era estimulada a "abertura das fronteiras agrícolas". Entretanto, não significa que os agricultores familiares não estejam preocupados com o meio ambiente ou que não preservem os recursos ambientais em suas propriedades.

É neste contexto que este estudo proporciona a reflexão que apesar de não conhecerem ou conhecerem parcialmente as informações constantes na legislação ambiental não significa que os agricultores familiares não preservem o meio ambiente. Para essa hipótese, a pesquisa aponta que a relação entre agricultor e natureza é de respeito e preocupação em garantir a qualidade do ecossistema. Afinal, os agricultores percebem que para a garantia de boas colheitas é necessário 


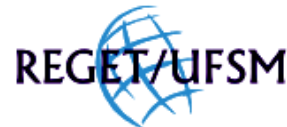

GODOY, WIZNIEWSKY, v(11), no 11, p. 2280-2290 , JUN, 2013.

Rev. Elet. em Gestão, Educação e Tecnologia Ambiental (e-ISSN: 2236-1170)

que o conjunto de fatores ambientais esteja em equilíbrio e com qualidade, para que assim a terra produza.

\section{CONCLUSÕES}

Para alcançarmos o desenvolvimento sustentável torna-se necessário conhecer e compreender como se forma e qual a percepção ambiental de uma determinada população, para que assim possa rever as relações com o meio ambiente, incorporando desta forma uma consciência mais ecológica e projetos mais sustentáveis ao cotidiano.

A atual preocupação da sociedade com o meio ambiente e a sustentabilidade ambiental implicam na necessidade de práticas sociais baseadas no direito à informação e a educação. Esta última, centralizada em práticas e propostas centradas na conscientização e na mudança de comportamento. Pode-se observar engajada apenas uma parcela da população ou/e que possui conhecimentos para entender toda a complexidade existente nos ecossistemas e a necessidade de preservação desta biodiversidade existente. Assim, torna-se imprescindível trabalhos que fomentam o diálogo e maneiras de levar as informações a todas as parcelas da sociedade, para que desta forma, cada indivíduo crie uma consciência ecológica e promova o fim do processo da degradação ambiental.

\section{REFERÊNCIAS BIBLIOGRÁFICAS}

AHRENS, S. O “Novo” Código Florestal Brasileiro: Conceitos Jurídicos Fundamentais. Trabalho voluntário apresentado no VIII Congresso Florestal Brasileiro. São Paulo: Sociedade Brasileira de Silvicultura. 2003.

BARRETO, A. de A. A questão da informação. São Paulo em Perspectiva, v. 8, n. 4. p. 3-8, 1994.

BRASIL. Lei n.⒋771, de 15 de setembro de 1965. Código Florestal Brasileiro. Institui o novo Código Florestal. Diário Oficial [da] República Federativa do Brasil, Brasília, DF. Disponível em> http://www.planalto.gov.br/ccivil_03/Leis/L4771.htm> Acesso em> 02 de set. de 2010.

BRASIL. Lei n.o 6. 938, de 31 de agosto de 1981. Dispõe sobre a Política Nacional do Meio Ambiente, seus fins e mecanismos de formulação e aplicação, e dá outras providências. Diário Oficial [da] República Federativa do Brasil, Brasília, DF. Disponível em: <http://www010.dataprev.gov.br/sislex/paginas/42/1981/6938.htm>. Acesso em: 02 set. 2010.

BRASIL. Lei no 12.727, de 17 de outubro de 2012. . Código Florestal Brasileiro. Altera a Lei n ${ }^{\circ} 12.651$, de 25 de maio de 2012 , que dispõe sobre a proteção da vegetação nativa; altera as Leis $\mathrm{n}^{\text {os }} 6.938$, de 31 de agosto de $1981,9.393$, de 19 de dezembro de 1996, e 11.428, de 22 de dezembro de 2006; e revoga as Leis $\mathrm{n}^{\circ}$ 4.771, de 15 de setembro de 1965 , e 7.754, de 14 de abril de 1989, a Medida Provisória $\mathrm{n}^{\circ}$ 2.166-67, de 24 de agosto de 2001, o item 22 do inciso II do art. 167 da Lei $n^{\circ} 6.015$, de 31 de dezembro de 1973 , e o $\S 2^{\circ}$ do art. $4^{\circ}$ da Lei $n^{\circ} 12.651$, de 25 de maio de $2012 .$. Diário Oficial [da] República Federativa do Brasil, Brasília, DF. Disponível em: <

http://www.jurisciencia.com/vademecum/legislacao-nacional/lei-12-727-de-17-de-outubro-de-2012-novo-codigoflorestal/1576/>. Acesso em: 22 jan. 2013.

BRASIL. Ministério do Planejamento, Orçamento e Gestão. Instituto Brasileiro de Geografia e Estatística. Contagem Populacional. Disponível em: <http://www.ibge.gov.br/home/>. Acesso em: 04 out. 2010. 


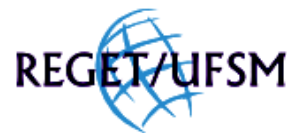

GODOY, WIZNIEWSKY, v(11), no 11, p. 2280-2290 , JUN, 2013.

Rev. Elet. em Gestão, Educação e Tecnologia Ambiental (e-ISSN: 2236-1170)

BRASIL. Secretaria do Meio Ambiente do Estado do Rio Grande do Sul/SEMA. Rio Grande do Sul. Mapas. Disponível em> http://www.sema.rs.gov.br/>. Acesso em: 10 jan. 2011.

COMISSÃO MUNDIAL SOBRE MEIO AMBIENTE E DESENVOLVIMENTO. Nosso Futuro Comum. Rio de Janeiro: Ed. Da Fundação Getúlio Vargas, 1988.

DIEGUES, A. C. S. Desenvolvimento sustentável ou sociedades sustentáveis da critica dos modelos aos novos paradigmas. São Paulo em Perspectiva, n. 6, p. 22-29, jan./jun., 1992.

FUNTOWICZ, S; MARCHI B. de. Ciencia Posnormal, Complejidad Reflexiva y Sustentabilidad. In: LEFF, E. La Complejidad Ambiental, Siglo XXI, Mexico, p. 54-84, 2000.

LEFF, E. Saber Ambiental, sustentabilidad, racionalidad, complejidad, poder. México, D.F., Siglo Ventiuno, 1998.

LEIS, H. R. Ambientalismo: um prometo realista-utópico para a política ambiental. In: VIOLA, E. J. et al. Meio ambiente, Desenvolvimento e Cidadania: desafios para as Ciências Sociais. São Paulo: Cortez; Florianópolis: Universidade Federal de Santa Catarina, 1995. p. 15-44.

JACOBI, P. Educação Ambiental, Cidadania e Sustentabilidade. Cadernos de Pesquisa, n. 118, mar. 2003.

JOLLIVET, M.; PAVÉ, A. (1992) - O Meio Ambiente: questões e perspectivas para a pesquisa. In: VIEIRA, P. F.; WEBER, J. (org). Gestão de Recursos Naturais Renováveis e Desenvolvimento - Novos desafios para a pesquisa ambiental. São Paulo, Editora Cortez, 1997.

GLIESSMAN, S. R. Agroecologia: processos ecológicos em agricultura sustentável. Porto Alegre: Editora da Universidade - UFRGS, 2000.

OlABUÉNAGA, J. I. R. Metodología de la investigación cualitativa. 2. ed. Espanha: Universidad de Deusto, 1999. (Serie Ciencias Sociales, vol.15)

ROHLEDER, D.; GRISON, A. J.; CALEGARI, R. Percepções Sobre o Desenvolvimento Socioeconômico da Região. Revista de Administração, v. 2, n. 3, 2003.

SANTOS, S. E. A Influência e a Percepção do Setor Automotivo na Sustentabilidade Ambiental da Região Metropolitana de Curitiba (RMC). 2007. Dissertação (Mestrado, área de concentração em Organizações e Desenvolvimento) Centro Universitário das Faculdades Associadas de Ensino, Curitiba, 2007.

SOARES, B. E. C.; NAVARRO, M. A.; FERREIRA, A. P. Desenvolvimento sustentado e consciência ambiental: natureza, sociedade e racionalidade. Ciências \& Cognição, v. 2, p. 42-49, 2004. 